\title{
Visfatin associated with major adverse cardiovascular events in patients with acute myocardial infarction
}

\author{
Meifan Zheng ${ }^{1,2}$, Nan Lu$^{1}$, Meixia Ren ${ }^{3}$ and Haifeng Chen ${ }^{1 *}$ (D)
}

\begin{abstract}
Background: Visfatin is an adipokine that related with the inflammation in atherosclerosis and the destabilization of atherosclerotic plaque. The aim of this study was to observe the relationship between visfatin and major adverse cardiovascular events (MACEs) in acute myocardial infarction (AMI) patients.

Methods: We enrolled a total of 238 patients (183 AMI and 55 control) who underwent coronary angiography. Patients with AMI were followed for an average of 19.3 months and 159 patients were finally included in the study.

Results: It was observed patients with AMI had higher serum visfatin levels than controls. The total incidence of MACEs was 11.32\% (18/159) in AMl patients. After calculation of the Youden index, the best cut-off value of visfatin on the curve of receiver-operating characteristic was $8.799 \mathrm{ng} / \mathrm{mL}$ for predicting the occurrence of MACEs. The occurrence of MACEs was elevated in high-visfatin group ( $\geq 8.799 \mathrm{ng} / \mathrm{mL})$ compared with low-visfatin group $(\leq 8.799 \mathrm{ng} / \mathrm{mL})$. The time to MACEs was correlated with visfatin $(\mathrm{HR}=1.235,95 \% \mathrm{Cl} 1.051-1.451, P=0.01)$ and highvisfatin group had an earlier time to MACEs and a shorter time of cumulative survival.
\end{abstract}

Conclusions: Increased serum visfatin levels were observed in AMl patients, and correlated with an earlier onset and higher incidence of MACEs.

Keywords: Acute myocardial infarction, Visfatin, Major adverse cardiovascular events

\section{Background}

Coronary atherosclerosis is a complex, long lasting and continuously evolving inflammatory disease [1]. Acute myocardial infarction (AMI) is an acute event of coronary atherosclerosis with a process involved with multiple inflammatory factors [2]. Visfatin is a novel adipokine found in 2005 by Fukuhara et al. [3]. Studies have demonstrated serum visfatin levels correlated with the presence of inflammatory state [4]. Visfatin may induce the secretion of the pro-inflammatory cytokines and could contribute to systemic and plaque inflammation in

\footnotetext{
* Correspondence: drchf1975@126.com

'Department of Cardiology, Fujian Provincial Clinical College, Fujian Medical University, Fuzhou 350001, Fujian, China

Full list of author information is available at the end of the article
}

atherosclerotic disorders through impacting macrophages $[5,6]$. Visfatin was found to be abundant in foam cells of unstable atherosclerotic plaques in AMI, and relevant to the destabilization of atherosclerotic plaque [7].

Previous studies have shown that visfatin was significantly increased in coronary atherosclerosis disease (CAD), and might be a promising biomarker for the diagnosis of CAD [8-11]. However, its relationship with the occurrence of severe coronary events remains unclear. Therefore, in this study, we sought to explore the association between serum visfatin levels and major adverse cardiovascular events (MACEs) in AMI.

(c) The Author(s). 2020 Open Access This article is licensed under a Creative Commons Attribution 4.0 International License, which permits use, sharing, adaptation, distribution and reproduction in any medium or format, as long as you give appropriate credit to the original author(s) and the source, provide a link to the Creative Commons licence, and indicate if changes were made. The images or other third party material in this article are included in the article's Creative Commons licence, unless indicated otherwise in a credit line to the material. If material is not included in the article's Creative Commons licence and your intended use is not permitted by statutory regulation or exceeds the permitted use, you will need to obtain permission directly from the copyright holder. To view a copy of this licence, visit http://creativecommons.org/licenses/by/4.0/. The Creative Commons Public Domain Dedication waiver (http://creativecommons.org/publicdomain/zero/1.0/) applies to the data made available in this article, unless otherwise stated in a credit line to the data. 


\section{Methods}

\section{Study population}

A total of 238 Chinese patients, who received coronary angiography in the department of cardiology in Fujian Provincial Hospital from January 2016 to September 2016 were recruited for this study. AMI group $(N=183,62$ ST-segment elevation myocardial infarction and 121 Non-ST segment elevation myocardial infarction) was defined with more than $50 \%$ stenosis in coronary arteries and positive troponin. The diagnostic criteria of AMI adopted the American College of Cardiology (ACC)/American Heart Association (AHA)/World Heart Federation (WHF)/European Society of Cardiology (ESC) guidelines established in 2012 [12]. Control group $(N=55)$ was defined with less than $50 \%$ stenosis in coronary arteries and negative troponin. The exclusion criteria as follows: valvular heart disease, myocarditis, cardiomyopathy, hypohepatia, thyroid dysfunction, end-stage chronic kidney disease, malignancy and hematological system diseases. The study complied with the Declaration of Helsinki and was approved by the ethical committee of Fujian Provincial Hospital (K2016-01001) (supplemental materials). Each participant provided written, informed consent before enrollment.

\section{Patient information and laboratory examination}

Patient information (such as age, gender, body mass index, hypertension, diabetes, hyperlipidemia, history of myocardial infarction and smoking) was recorded by standardized form. The cardiac biomarkers (cardiac troponin-I, N-terminal pro-brain natriuretic peptide) and thrombin index (fibrinogen, D-dimer) were detected immediately after admission. Other vein biochemical index were detected in the next morning (fasting for 8$12 \mathrm{~h}$ ) after admission, including glucose, albumin, creatinine, triglycerides, total cholesterol, high-density lipoprotein, low-density lipoprotein, apolipoprotein-a, apolipoprotein-b. The above indicators were completed by the laboratory department of our hospital and we obtain laboratory parameter from the patients medical records at index admission.

\section{Visfatin detection}

Blood samples were collected into EDTA-containing tubes from subjects at baseline at least 8-12 h fasting before coronary angiography and centrifuged at $700 \mathrm{~g}$. Serum concentration of visfatin was determined by enzyme-linked immunosorbent assay with the EK-00380 human visfatin kit (Phoenix Pharmaceuticals, Belmont, CA). The operation steps followed the instructions strictly.

\section{Coronary angiography}

Standard Judkins technique was carried out in the coronary arteriography and all coronary artery stenosis was imaged from multiple projections. Two expert cardiologists who were blinded to the patients' clinical and laboratory data reviewed the coronary angiography and evaluated the coronary atherosclerotic lesion severity independently. According to the number of stenosis which was detected $\geq 50 \%$ of the lumen diameter of a coronary artery, we divided it into single-vessel lesion, double vessel lesion and multi-vessel lesion.

\section{Follow-up}

In this study, all of AMI patients were followed up after admission using a standardized protocol that included outpatient follow up, telephone contacts and hospital data. The endpoints was MACEs, including death of cardiovascular events, nonfatal myocardial infarction (reMI), target lesion revascularization (percutaneous coronary intervention or coronary artery bypass graft) and re-admission due to advanced heart failure.

\section{Statistical analysis}

The version 22.0 SPSS software suite was used for all statistical analyses. Continuous variables was tested for normality test. Normally distributed data was expressed as mean \pm standard deviation and skewed distributions data was expressed as median with inter-quartile range. Intergroup comparisons of clinical data were performed with student's t-test (normally distributed data) or the Mann-Whitney U test (skewed data). Multiple groups comparisons of clinical data were performed with the analysis of variance (normally distributed data) or the Kruskal-Wallis $\mathrm{H}$ test (skewed data). Categorical variables were presented as number (percentage) and analyzed by chi-square statistic test. Binary Logistic regression was used to analyze the factors which were correlated with the occurrence of MACEs in a stepwise backward conditional manner. Receiver-operating characteristic (ROC) curves was used to evaluated the predictive value of visfatin for the occurrence of MACEs. Cox regression analysis was used to analyze the factors which were correlated with the time to MACEs and Kaplan-Meier curves was used to estimate the survival time between high and low visfatin group with a logrank test. For all analyses, two tailed $P$ values $<0.05$ were.

\section{Results}

Baseline characteristics

A total of 238 participants (183 AMI and 55 control group, mean age $64.40 \pm 10.68$ years). The baseline characteristics of participants were summarized in Table 1. Compared with control group, AMI group had more 
Table 1 Clinical characteristics of control and AMI patients

\begin{tabular}{|c|c|c|c|}
\hline Variables & Control $(n=55)$ & $\mathrm{AMI}(n=183)$ & $P$ value \\
\hline Male $(n, \%)$ & $33(60.00 \%)$ & 155 (84.70\%) & $<0.001$ \\
\hline Age (years) & $66.87 \pm 9.45$ & $63.66 \pm 10.94$ & 0.036 \\
\hline $\mathrm{BMI}\left(\mathrm{kg} / \mathrm{m}^{2}\right)$ & $23.48 \pm 2.32$ & $23.83 \pm 2.84$ & 0.349 \\
\hline Current smoking (n, \%) & $17(30.90 \%)$ & $98(53.55 \%)$ & 0.003 \\
\hline Diabetes (n, \%) & $8(14.54 \%)$ & $46(25.14 \%)$ & 0.100 \\
\hline Hypertention (n, \%) & $15(27.27 \%)$ & $96(52.40 \%)$ & 0.001 \\
\hline Hyperlipidemia (n, \%) & $14(25.45 \%)$ & $55(30.05 \%)$ & 0.510 \\
\hline SBP on admission (mmHg) & $137.69 \pm 21.78$ & $128.69 \pm 19.80$ & 0.004 \\
\hline DBP on admission $(\mathrm{mmHg})$ & $74.34 \pm 10.52$ & $75.88 \pm 11.85$ & 0.358 \\
\hline Glucose (mmol/L) & $5.57 \pm 1.53$ & $6.23 \pm 2.04$ & 0.012 \\
\hline Albumin (g/L) & $40.87 \pm 4.32$ & $39.45 \pm 4.26$ & $<0.001$ \\
\hline Triglycerides (mmol/L) & $1.38 \pm 0.62$ & $1.52 \pm 0.86$ & 0.168 \\
\hline Total cholesterol (mmol/L) & $4.22 \pm 0.91$ & $4.28 \pm 1.00$ & 0.659 \\
\hline $\mathrm{HDL}-\mathrm{C}(\mathrm{mmol} / \mathrm{L})$ & $1.22 \pm 0.34$ & $1.05 \pm 0.29$ & $<0.001$ \\
\hline LDL-C (mmol/L) & $2.58 \pm 0.79$ & $2.77 \pm 0.89$ & 0.133 \\
\hline Apo A (g/L) & $1.29 \pm 0.24$ & $1.15 \pm 0.36$ & 0.001 \\
\hline Apo B (g/L) & $0.83 \pm 0.23$ & $0.92 \pm 0.26$ & 0.010 \\
\hline Creatinine (umol/L) & $73.29 \pm 18.83$ & $81.58 \pm 25.99$ & 0.010 \\
\hline Fibrinogen (g/L) & $3.35 \pm 0.84$ & $4.24 \pm 1.23$ & $<0.001$ \\
\hline D-Dimer (mg/L) & $0.3(0.19,0.44)$ & $0.46(0.30,0.79)$ & $<0.001$ \\
\hline $\mathrm{CTnl}(\mathrm{ng} / \mathrm{mL})$ & $0.01(0.00,0.01)$ & $5.62(1.10,28.28)$ & $<0.001$ \\
\hline NT-proBNP (pg/mL) & $124(59.00,200.00)$ & $690(278.00,1855.00)$ & $<0.001$ \\
\hline Visfatin (ng/mL) & $6.74(5.76,7.53)$ & $7.70(6.57,9.82)$ & $<0.001$ \\
\hline
\end{tabular}

males, higher smoking history and the prevalence of hypertension, but was younger and had lower systolic blood pressure. The AMI group had significantly higher fasting blood glucose, ApoB, creatinine, fibrinogen, DDimer, CTnI, NT-proBNP (all $P<0.05$ ) and lower albumin, HDL-C, ApoA (all $P<0.05$ ) compared with control group. However, there were no statistical significant in body mass index (BMI), diabetes, hyperlipidemia, diastolic blood pressure, triglycerides, total cholesterol, LDL-C between two groups (all $P>0.05$ ). Meanwhile, serum visfatin levels were significantly higher in AMI than control group $[7.70(6.57,9.82)$ vs $6.74(5.76,7.53)$, $P<0.01]$.

\section{Serum visfatin levels in different number of coronary lesions}

There were 70 (38.25\%) single vessel coronary lesions, 57 (31.15\%) double vessel coronary lesions, 56 (30.60\%) multiple vessel coronary lesions in AMI patient after coronary angiography (Table 2). As indicated by MannWhitney $U$ test, serum visfatin levels of single, double and multiple vessel coronary lesions were significantly higher than control group $(P<0.05)$. However, Kruskal- wallis $\mathrm{H}$ test analysis showed that there were no statistically significant difference between the groups $(P>0.05)$.

\section{MACEs during follow-up}

A total of 183 patients with AMI were followed up with the period of 16-24 months (average 19.3 months), 24 patients were excluded because of various reasons, only 159 patients received follow-up. Total 18 (11.32\%) patients presented with MACEs. Of these, 7 (4.40\%) suffered non-fatal re-MI, 2 (1.26\%) suffered heart failure, 9 (5.65\%) were dead of cardiovascular events.

A total of 159 patients were divided into MACEs group and non-MACEs group, the clinical characteristics analysis showed that MACEs group had significantly

Table 2 Serum visfatin levels in different number of coronary lesions

\begin{tabular}{lll}
\hline Variables & Case $(\mathrm{n})$ & Visfatin $(\mathrm{ng} / \mathrm{mL})$ \\
\hline control group & 55 & $6.74(5.76,7.53)$ \\
Single vessel coronary lesions & 70 & $7.68(6.37,9.65)^{*}$ \\
Double vessel coronary lesions & 57 & $7.67(6.66,8.92)^{*}$ \\
Multiple vessel coronary lesions & 56 & $8.14(6.63,11.60)^{*}$ \\
\hline
\end{tabular}

* Compared with control group, $P<0.05$ 
higher age, diabetes, creatinine, NT-proBNP, serum visfatin levels (all $P<0.05$ ) and lower albumin, triglycerides, total cholesterol, LVEF (all $P<0.05$ ) than nonMACEs group. In contrast, no significant differences were observed in gender, smoking, hypertension, hyperlipaemia, history of MI, type of AMI, BMI, systolic pressure, diastolic pressure, glucose, HDL-C, LDL-C, ApoA, ApoB, fibrinogen, D-Dimer and CTnI (Table 3).

\section{Correlation of visfatin with MACEs}

Binary logistic regression was used to analyze the predictors of MACEs, after adjusting for gender and age, visfatin, total cholesterol, LDL-C and diabetes were correlated with the occurrence of MACEs in AMI patients. (Table 4).

Contribution of visfatin in predicting the occurrence of MACEs was assessed by ROC curves which showed that visfatin had a 0.751 area under curve (AUC) $(95 \% \mathrm{CI}$ $0.652-0.849, P=0.010)$ with a $78.8 \%$ sensitivity and $68.8 \%$ specificity. The traditional risk factors, including
Table 4 Risk factors of MACEs in AMI

\begin{tabular}{llll}
\hline Variables & OR & $95 \% \mathrm{Cl}$ & $P$ Value \\
\hline Gender & 0.225 & $0.045-1.119$ & 0.068 \\
Age & 1.025 & $0.932-1.127$ & 0.614 \\
Visfatin & 1.278 & $1.037-1.574$ & 0.021 \\
Total cholesterol & 0.028 & $0.001-0.521$ & 0.017 \\
LDL-C & 2.990 & $1.142-7.825$ & 0.041 \\
Diabetes & 3.766 & $1.053-7.473$ & 0.041 \\
\hline
\end{tabular}

smoking, hypertension, diabetes, hyperlipidemia and BMI had a 0.733 AUC $(95 \%$ CI $0.619-0.847, P=0.010)$ with a $72.2 \%$ sensitivity and $66.7 \%$ specificity. While, a combined model consisting of visfatin and traditional risk factors (smoking, hypertension, diabetes, hyperlipidemia, BMI) showed a 0.783 AUC with a $72.2 \%$ sensitivity and $73.8 \%$ specificity (Fig. 1 ).

After calculation of the Youden index, the best cut-off value of visfatin on the ROC curves was $8.799 \mathrm{ng} / \mathrm{mL}$ for predicting the occurrence of MACEs. Patients were

Table 3 Clinical characteristics between MACEs and non-MACEs

\begin{tabular}{|c|c|c|c|}
\hline Variables & MACEs $(n=18)$ & non-MACEs $(n=141)$ & $P$ value \\
\hline Male (n, \%) & $13(72.22 \%)$ & $122(86.52 \%)$ & 0.139 \\
\hline Age (years) & $68.89 \pm 8.99$ & $62.23 \pm 10.58$ & 0.008 \\
\hline Current smoking $(\mathrm{n}, \%)$ & $8(44.44 \%)$ & $78(52.48 \%)$ & 0.384 \\
\hline Hypertension (n, \%) & $13(72.22 \%)$ & $70(49.64 \%)$ & 0.066 \\
\hline Hyperlipidemia (n, \%) & $3(16.67 \%)$ & $44(31.20 \%)$ & 0.181 \\
\hline Diabetes (n, \%) & $9(50.00 \%)$ & 32 (22.69\%) & 0.019 \\
\hline History of Ml (n, \%) & $3(16.67 \%)$ & $18(12.67 \%)$ & 0.655 \\
\hline STEMI $(n, \%)$ & $3(16.67 \%)$ & $50(35.40 \%)$ & 0.093 \\
\hline $\mathrm{BMI}\left(\mathrm{kg} / \mathrm{m}^{2}\right)$ & $24.35 \pm 2.55$ & $33.85 \pm 2.98$ & 0.450 \\
\hline SBP on admission (mmHg) & $124.61 \pm 17.44$ & $128.84 \pm 19.54$ & 0.349 \\
\hline DBP on admission $(\mathrm{mmHg})$ & $74.05 \pm 13.76$ & $75.83 \pm 11.61$ & 0.606 \\
\hline Glucose (mmol/L) & $7.06 \pm 3.06$ & $6.07 \pm 1.76$ & 0.192 \\
\hline Albumin $(\mathrm{g} / \mathrm{L})$ & $37.44 \pm 4.30$ & $39.84 \pm 4.19$ & 0.037 \\
\hline Triglycerides (mmol/L) & $1.21 \pm 0.49$ & $1.54 \pm 0.80$ & 0.021 \\
\hline Total cholesterol (mmol/L) & $3.77 \pm 0.97$ & $4.35 \pm 0.99$ & 0.030 \\
\hline $\mathrm{HDL}-\mathrm{C}(\mathrm{mmol} / \mathrm{L})$ & $0.92 \pm 0.26$ & $1.05 \pm 0.27$ & 0.068 \\
\hline $\mathrm{LDL}-\mathrm{C}(\mathrm{mmol} / \mathrm{L})$ & $2.45 \pm 0.78$ & $2.84 \pm 0.88$ & 0.061 \\
\hline Apo A $(g / L)$ & $1.19 \pm 0.95$ & $1.14 \pm 0.22$ & 0.535 \\
\hline Apo B (g/L) & $0.87 \pm 0.23$ & $0.95 \pm 0.25$ & 0.146 \\
\hline Creatinine (umol/L) & $101.67 \pm 46.63$ & $79.88 \pm 22.59$ & 0.001 \\
\hline Fibrinogen $(g / L)$ & $4.04 \pm 0.86$ & $4.24 \pm 1.32$ & 0.634 \\
\hline D-Dimer (mg/L) & $0.52(0.36,1.48)$ & $0.42(0.25,0.79)$ & 0.084 \\
\hline $\mathrm{CTnl}(\mathrm{ng} / \mathrm{mL})$ & $8.44(1.09,40.35)$ & $4.77(1.02,28.74)$ & 0.518 \\
\hline NT-proBNP (pg/mL) & $1751(372.00,9262.50)$ & $575(248.00,1423.50)$ & 0.025 \\
\hline LVEF (\%) & $0.51 \pm 0.02$ & $0.57 \pm 0.01$ & 0.006 \\
\hline Visfatin $(\mathrm{ng} / \mathrm{mL})$ & $9.89(8.66,12.80)$ & $7.53(6.53,8.94)$ & 0.001 \\
\hline
\end{tabular}




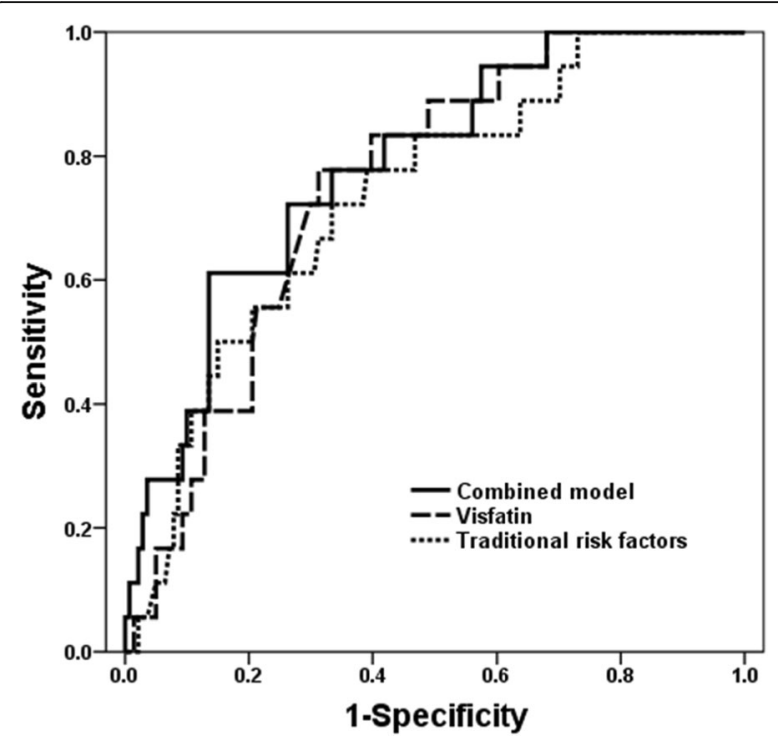

Fig. 1 Receiver-operating characteristic curves of visfatin, traditional risk factors, and combined model for predicting MACEs

divided into high-visfatin group (serum visfatin levels $\geq 8.799 \mathrm{ng} / \mathrm{mL}$ ) and low-visfatin group (serum visfatin levels $\leq 8.799 \mathrm{ng} / \mathrm{mL}$ ) based on the threshold. By chisquare test, we found that the occurrence of MACEs was elevated in high-visfatin group compared with lowvisfatin group, and the occurrence of non-fatal re-MI was elevated in high-visfatin group $(P=0.049$, Table 5$)$.

\section{Survival curve analysis of AMI patients in follow-up}

The univariate COX proportional hazards regression analysis showed that age, diabetes, glucose, albumin, total cholesterol, creatinine, D-Dimer, LVEF and visfatin were associated with the time to MACEs. While, the multivariate Cox proportional hazards regression analysis showed that after adjusting for gender and age, only visfatin correlated with the time to MACEs (Table 6). Further, the Kaplan-Meier cuvers demonstrated that the time to MACEs was earlier in high-visfatin group compared with low-visfatin group, and the cumulative survival time was shorter $(P=0.021$, Fig. 2$)$.

\section{Discussion}

In the present study, we found that serum visfatin level was elevated in AMI patients and contributed to MACEs incidence. Visfatin, total cholesterol, LDL-C and diabetes
Table 6 Univariate and Multivariate Cox Regression of MACEs

\begin{tabular}{lllll}
\hline Variables & Univariate COX & $P$ & Multivariate COX & $P$ \\
& HR $(95 \% \mathrm{Cl})$ & value & HR $(95 \% \mathrm{Cl})$ & value \\
\hline Age & $1.063(1.012,1.117)$ & 0.014 & $1.011(0.952,1.075)$ & 0.715 \\
Gender & $0.435(0.155,1.222)$ & 0.114 & $2.447(0.712,8.407)$ & 0.155 \\
Diabetes & $3.061(1.215,7.712)$ & 0.018 & $0.466(0.139,1.566)$ & 0.217 \\
Glucose & $1.208(1.021,1.430)$ & 0.028 & $1.152(0.953,1.392)$ & 0.143 \\
Albumin & $0.885(0.792,0.988)$ & 0.029 & $1.020(0.870,1.196)$ & 0.803 \\
Total cholesterol & $0.576(0.352,0.942)$ & 0.028 & $0.595(0.336,1.054)$ & 0.075 \\
Creatinine & $1.018(1.007,1.029)$ & 0.001 & $1.010(0.997,1.022)$ & 0.124 \\
D-Dimer & $1.531(1.178,1.990)$ & 0.001 & $1.333(0.955,1.862)$ & 0.091 \\
LVEF & $0.014(0.001,0.274)$ & 0.005 & $0.011(0.000,4.913)$ & 0.148 \\
Visfatin & $1.226(1.076,1.398)$ & 0.002 & $1.235(1.051,1.451)$ & 0.010 \\
\hline
\end{tabular}

were correlated with the occurrence of MACEs in AMI patients. A combined model consisting of visfatin and traditional risk factors showd a higher specificity in predicting MACEs. The occurrence of MACEs was elevated in high-visfatin group, especially in non-fatal re-MI. Visfatin was correlated with the onset to MACEs and high serum visfatin level was associated with an earlier onset of MACEs.

Visfatin (also referred as Pre-B cell colony enhancing factor and nicotinamide phosphoribosyltransferase) is a member of adipokine with a molecular weight about $52 \mathrm{kD}$ [13]. Studies have demonstrated that visfatin could promote insulin and pro-inflammatory cytokines secretions $[5,14]$, and it is a pleiotropic protein implicated in the pathophysiology of obesity, metabolic disease, diabetes and cancer [15-18]. Dahl et al. firstly reported that visfatin was markedly enhanced in symptomatic carotid atherosclerotic plaques [19]. Subsequently, various studies provided that visfatin was closely related with cardiovascular disease [20-26]. Horbal et al. showd that the odds of severe hypertension were in accordance with the levels of visfatin [21]. Bobbert et al. discovered high visfatin in nonischemic dilated congestive cardiomyopathy (DCM) patients was associated with a favorable outcome and improvement in functional status [22]. In addition, serum visfatin level was observed to be significantly higher in premature coronary artery disease and coronary slow flow (CSF) [23, 24]. Notably, an augmented level of visfatin in STEMI was positively correlated with the number of coronary lesions $[10,25]$. We also found

Table 5 MACEs of high-visfatin group and low-visfatin group

\begin{tabular}{llll}
\hline Variables $(\mathrm{n}, \%)$ & Visfatin $\geq 8.799 \mathrm{ng} / \mathrm{ml}(n=58)$ & Visfatin $\leq 8.799 \mathrm{ng} / \mathrm{ml}(n=101)$ & $P$ value \\
\hline MACEs & $11(18.96 \%)$ & $7(6.93 \%)$ & 0.021 \\
non-fatal re-Ml & $5(8.62 \%)$ & $2(1.96 \%)$ & 0.049 \\
heart failure & $1(1.72 \%)$ & $1(0.99 \%)$ & 0.698 \\
death of cardiovascular events & $5(8.62 \%)$ & $4(3.96 \%)$ & 0.227 \\
\hline
\end{tabular}




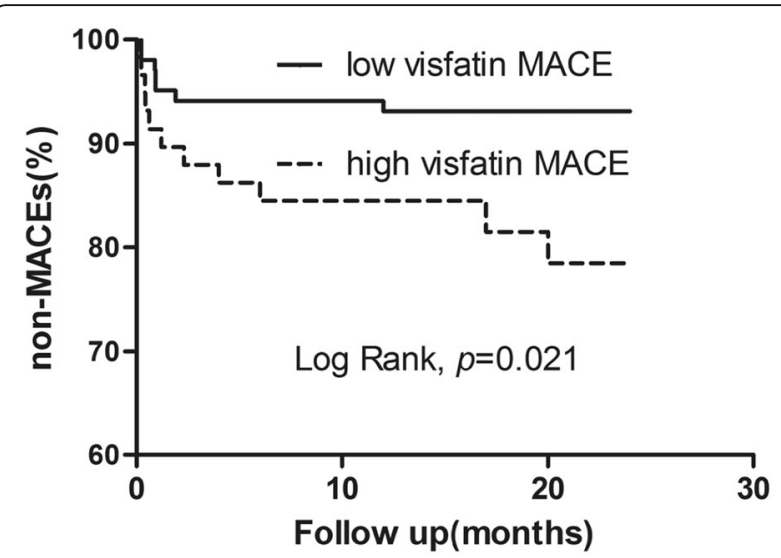

Fig. 2 The cumulative event-free survival analysis of high-visfatin group and low-visfatin group

an increase of serum visfatin levelin AMI patients. However, there was no statistically significant difference in the number of coronary lesions, possibly because of the limited number of subjects in our study.

In this study, an average of 19.3 months of follow-up was conducted for 159 patients with AMI. A total of 18 (11.32\%) patients had MACEs in follow-up, among those, 7 (4.40\%) suffered non-fatal re-MI, 2 (1.26\%) suffered heart failure, 9 (5.65\%) were dead of cardiovascular events. Binary logistic analysis showed that visfatin, total cholesterol, LDL-C and diabetes were all associated with the occurrence of MACEs.

We applied ROC curves to evaluate the contribution of traditional risk factors (smoking, hypertension, diabetes, hyperlipidemia and body mass index) and visfatin in predicting MACEs. We discovered that visfatin and traditional risk factors had a specificity of 68.8 and $66.7 \%$ in predicting MACEs,respectively, while a combined model consisting of all factors showed a $73.8 \%$ specificity. The combined model greatly improved the predictive of MACEs and clinical practical value. Our data showed the occurrence of MACEs was elevated in high-visfatin group, especially in non-fatal re-MI.

Multivariate Cox proportional hazards regression analysis suggested that visfatin was correlated with the onset to MACEs. Kaplan-Meier curves demonstrated that the onset to MACEs was earlier in high-visfatin group compared with low-visfatin group, and the cumulative survival time was shorter. Although the mechanisms of visfatin in coronary atherosclerotic heart disease remain unclear, previous researchers had shown the increased serum visfatin level after drug-eluting stents (DES) placement was independently associated with in-stent restenosis (ISR) [26]. Visfatin could promote the production of interleukin (IL)- 6 and intercellular adhesion molecule-1 (ICAM-1) and regulate nuclear factor (NF)kappaB, which resulted in the apoptosis of endothelial progenitor cells (EPCs) [5]. Visfatin could also increase the expression of metal matrix proteinase (MMP)- 8 in macrophages, promote collagen degradation and the plaques vulnerability index [27]. Visfatin was indicated to be abundant in foam cells within unstable atherosclerotic plaques [7]. Therefore, we presume visfatin may contribute to the MACEs by regulating the inflammation, apoptosis and collagen degradation, and we will take further clinical research and basic experimental to investigate the possible mechanism behind.

There were several limitations in the present study. First, the subjects recruited were hospitalized in single centre, lacking regional and ethnic comparisons. Second, the sample size was limited and the follow-up time was relatively short. Third, lacking of dynamic monitoring of visfatin levels during the follow-up period.

\section{Conclusions}

Our findings support previous observations of serum visfain level was elevated in acute myocardial infarction patients. In addition, our study demonstrated that visfatin was correlated with an earlier onset and higher incidence of MACEs.

\section{Supplementary information}

Supplementary information accompanies this paper at https://doi.org/10. 1186/s12872-020-01549-3.

Additional file 1. Ethics approval.

\section{Abbreviations}

AMl: Acute myocardial infarction; Apo A: Apolipoprotein-a; Apo B: Apolipoprotein-b; AUC: Area under curve; BMl: Body mass index; CAD: Coronary atherosclerosis disease; CTnl: Cardiac troponin-l; HDL-C: Highdensity lipoprotein; LDL-C: Low-density lipoprotein; LVEF: Left ventricular ejection fraction; MACEs: Major adverse cardiovascular events; MI: Acute myocardial infarction; NT-proBNP: N-terminal pro-brain natriuretic peptide; ROC: Receiver-operating characteristic

\section{Acknowledgements}

The authors thank Fujian Provincial Hospital and all the people involved in this study.

\section{Authors' contributions}

CHF and ZMF were involved in the experimental design, coordination and drafting the manuscript. ZMF, LN and RMX performed the experiments. ZMF and LN conducted date analysis and prepared the manuscript. CHF and RMX revised the manuscript. All authors read and approved the final manuscript.

\section{Funding}

This work was supported by National Natural Science Foundation of China (No.: 81470021, No.:81800364), the Key Project of Cultivating Young Talent in Fujian provincial health and family planning commission (No.: 2016-ZQN-8) and high-level hospital foster grants from Fujian Provincial Hospital, Fujian province, China. All funders provided financial support in our study.

\section{Availability of data and materials}

The datasets generated and analysed during the current study are not publicly available due to protection of individual privacy, but are available from the corresponding author on reasonable request. 


\section{Ethics approval and consent to participate}

The study was approved by the Ethics Committee of Fujian Provincal Hospital (K2016-01-001, Fujian,China). The patients and/or guardians signed an informed consent.

\section{Consent for publication}

Not applicable.

\section{Competing interests}

The authors declare that they have no competing interests.

\section{Author details}

${ }^{1}$ Department of Cardiology, Fujian Provincial Clinical College, Fujian Medical University, Fuzhou 350001, Fujian, China. ${ }^{2}$ Department of Cardiology, Hainan West Central Hospital, Danzhou 571700, Hainan, China. ${ }^{3}$ Fujian Key Laboratory of Geriatrics, Department of Geriatric Medicine, Fujian Provincial Hospital, Fujian Medical University, Fuzhou 350001, Fujian, China.

Received: 15 January 2020 Accepted: 24 May 2020

Published online: 05 June 2020

\section{References}

1. Boudoulas KD, Triposciadis F, Geleris P, Boudoulas H. Coronary atherosclerosis: pathophysiologic basis for diagnosis and management. Prog Cardiovasc Dis. 2016;58(6):676-92.

2. Ong SB, Hernandez-Resendiz S, Crespo-Avilan GE, Mukhametshina RT, Kwek XY, Cabrera-Fuentes HA, Hausenloy DJ. Inflammation following acute myocardial infarction: multiple players, dynamic roles, and novel therapeutic opportunities. Pharmacol Ther. 2018;186:73-87.

3. Fukuhara A, Matsuda M, Nishizawa M, Segawa K, Tanaka M, Kishimoto K, Matsuki Y, Murakami M, Ichisaka T, Murakami H, et al. Visfatin: a protein secreted by visceral fat that mimics the effects of insulin. Science. 2005; 307(5708):426-30.

4. Hognogi LD, Simiti LV. The cardiovascular impact of visfatin - an inflammation predictor biomarker in metabolic syndrome. Clujul Med. 2016; 89(3):322-6.

5. Sun L, Chen S, Gao H, Ren L, Song G. Visfatin induces the apoptosis of endothelial progenitor cells via the induction of pro-inflammatory mediators through the NF-kappaB pathway. Int J Mol Med. 2017:40(3): $637-46$

6. Halvorsen B, Espeland MZ, Andersen GØ, Yndestad A, Sagen EL, Rashidi A, Knudsen EC, Skjelland M, Skagen KR, Krohg-Sørensen K, et al. Increased expression of NAMPT in PBMC from patients with acute coronary syndrome and in inflammatory M1 macrophages. Atherosclerosis. 2015;243(1):204-10.

7. Chiu CA, Yu TH, Hung WC, Lu LF, Chung FM, Tsai IT, Yang CY, Hsu CC, Lu $Y C$, Houng JY, et al. Increased expression of visfatin in monocytes and macrophages in male acute myocardial infarction patients. Mediat Inflamm. 2012:2012:469852

8. Wang X-H, Dou L-Z, Gu C, Wang X-Q. Plasma levels of omentin-1 and visfatin in senile patients with coronary heart disease and heart failure. Asian Pac J Trop Med. 2014;7(1):55-62.

9. Saddi-Rosa P, Oliveira C, Crispim F, Giuffrida FM, de Lima V, Vieira J, Doria A, Velho G, Reis A. Association of circulating levels of nicotinamide phosphoribosyltransferase (NAMPTNisfatin) and of a frequent polymorphism in the promoter of the NAMPT gene with coronary artery disease in diabetic and non-diabetic subjects. Cardiovasc Diabetol. 2013;12:119.

10. Fadaei R, Parvaz E, Emamgholipour S, Moradi N, Vatannejad A, Najafi M, Doosti M. The mRNA expression and circulating levels of Visfatin and their correlation with coronary artery disease severity and 25-Hydroxyvitamin D. Horm Metab Res. 2016;48(4):269-74.

11. Yu F, Li J, Huang Q, Cai H. Increased peripheral blood Visfatin concentrations may be a risk marker of coronary artery disease: a metaanalysis of observational studies. Angiology. 2018;69(9):825-34.

12. Thygesen $K$, Alpert JS, Jaffe AS, Simoons ML, Chaitman BR, White HD. Joint ESCAAHAWHFTFftUDoMl, Katus HA, Lindahl B, morrow DA et al. third universal definition of myocardial infarction. Circulation. 2012; 126(16):2020-35.

13. Wang $T$, Zhang $X$, Bheda $P$, Revollo JR, Imai S, Wolberger $C$. Structure of Nampt/PBEF/visfatin, a mammalian NAD+ biosynthetic enzyme. Nat Struct Mol Biol. 2006;13(7):661-2.
14. Spinnler R, Gorski T, Stolz K, Schuster S, Garten A, Beck-Sickinger AG, Engelse MA, de Koning EJ, Korner A, Kiess W, et al. The adipocytokine Nampt and its product NMN have no effect on beta-cell survival but potentiate glucose stimulated insulin secretion. PLoS One. 2013:8(1):e54106.

15. Kieswich J, Sayers SR, Silvestre MF, Harwood SM, Yaqoob MM, Caton PW. Monomeric eNAMPT in the development of experimental diabetes in mice: a potential target for type 2 diabetes treatment. Diabetologia. 2016;59(11): 2477-86.

16. Carbone F, Liberale L, Bonaventura A, Vecchie A, Casula M, Cea M, Monacelli F, Caffa I, Bruzzone S, Montecucco F, et al. Regulation and function of extracellular Nicotinamide Phosphoribosyltransferase/Visfatin. Compr Physiol. 2017;7(2):603-21.

17. Dahl TB, Holm S, Aukrust P, Halvorsen B. Visfatin/NAMPT: a multifaceted molecule with diverse roles in physiology and pathophysiology. Annu Rev Nutr. 2012:32:229-43.

18. Yan X, Zhao J, Zhang R. Visfatin mediates doxorubicin resistance in human colorectal cancer cells via up regulation of multidrug resistance 1 (MDR1). Cancer Chemother Pharmacol. 2017;80(2):395-403.

19. Dahl TB, Yndestad A, Skjelland M, Oie E, Dahl A, Michelsen A, Damas JK, Tunheim SH, Ueland T, Smith C, et al. Increased expression of visfatin in macrophages of human unstable carotid and coronary atherosclerosis: possible role in inflammation and plaque destabilization. Circulation. 2007; 115(8):972-80

20. Ashraf H, Soltani D, Sobh-Rakhshankhah A, Jafari S, Boroumand MA Goudarzi V, Vasheghani Farahani A, Masoudkabir F. Visfatin as marker of isolated coronary artery ectasia and its severity. Cytokine. 2019:113:216-20.

21. Horbal SR, Seffens W, Davis AR, Silvestrov N, Gibbons GH, Quarells RC, Bidulescu A. Associations of Apelin, Visfatin, and urinary 8-Isoprostane with severe hypertension in African Americans: the MH-GRID study. Am J Hypertens. 2016;29(7):814-20.

22. Bobbert P, Kuhl U, Poller W, Rauch U, Schultheiss HP, Skurk C. Nicotinamide phosphoribosyltransferase/pre-B-cell colony enhancing factor/visfatin plasma levels and clinical outcome in patients with dilated cardiomyopathy. J Card Fail. 2015;21(4):330-8.

23. Smekal A, Vaclavik J, Stejskal D, Benesova K, Jarkovsky J, Svobodova G, Richterova R, Svestak M, Taborsky M. Plasma levels and leucocyte RNA expression of adipokines in young patients with coronary artery disease, in metabolic syndrome and healthy controls. Cytokine. 2017.

24. Cakmak HA, Aslan S, Yalcin AA, Akturk IF, Yalcin B, Uzun F, Ozturk D, Erturk M, Gul M. Relationship between serum visfatin levels and coronary slowflow phenomenon. Herz. 2015;40(6):921-8.

25. Lu LF, Wang CP, Yu TH, Hung WC, Chiu CA, Chung FM, Tsai IT, Yang CY, Cheng YA, Lee YJ, et al. Interpretation of elevated plasma visfatin concentrations in patients with ST-elevation myocardial infarction. Cytokine. 2012:57(1):74-80.

26. Wu XA, Xie G, Li XQ, Wu HT, Wang X. The value of serum visfatin in predicting in-stent restenosis of drug-eluting stents. Clin Chim Acta. 2018; 479:20-4.

27. Li B, Zhao Y, Liu H, Meng B, Wang J, Qi T, Zhang H, Li T, Zhao P, Sun H, et al. Visfatin destabilizes atherosclerotic plaques in Apolipoprotein Edeficient mice. PLoS One. 2016;11(2):e0148273.

\section{Publisher's Note}

Springer Nature remains neutral with regard to jurisdictional claims in published maps and institutional affiliations.

\section{Ready to submit your research? Choose BMC and benefit from:}

- fast, convenient online submission

- thorough peer review by experienced researchers in your field

- rapid publication on acceptance

- support for research data, including large and complex data types

- gold Open Access which fosters wider collaboration and increased citations

- maximum visibility for your research: over $100 \mathrm{M}$ website views per year

At $\mathrm{BMC}$, research is always in progress.

Learn more biomedcentral.com/submissions 